Os Jogos Paralímpicos de Inverno de 2022 estão agendados para 4 a 13 de março em Pequim. Serão reutiliza-

\title{
$\sim$ Desportos de Inverno Adaptados
}

Dra. Margarida Mota Freitas, Dra. Sara Antunes, Dra. Rute Pereira

Interna de Formação Específica de Medicina Física e de Reabilitação, Hospital Garcia de Orta, Almada

\section{RESUMO / ABSTRACT}

A prática de exercício físico está recomendada para a toda a população, incluindo as pessoas portadoras de deficiência motora, sensorial ou cognitiva. Atualmente são muitas as modalidades disponíveis no desporto adaptado, incluindo os desportos de inverno. A participação em desporto adaptado mostrou melhorar a capacidade cardiovascular, contribuir para a integração na comunidade e diminuição das queixas álgicas, levando a melhoria da qualidade de vida. Os desportos de inverno paralímpico com mais praticantes são o esqui alpino, o esqui nórdico e o para-hóquei no gelo. Os desafios na abordagem médica do atleta paralímpico de desportos de inverno incluem a necessidade de adequar o material ao atleta, prevenir lesões traumáticas agudas e tratar agudizações relacionadas com a patologia crónica.

Physical exercise is generally recommended. Specific populations have particular needs, but physical exercise is also highly recommended for people with motor, sensory or cognitive disabilities. There are currently adaptive sports, including winter sports. Participation in adaptive sports improves cardiovascular capacity, contributes to integration in the community and decreases pain intensity, leading to improved quality of life. Alpine skiing, Nordic skiing and ice hockey are the most popular paralympic winter sports. The medical teams working with Paralympic winter sports athletes face several challenges such as the need to tailor the adaptative material to the athlete, prevent acute traumatic injuries and treat chronic diseases.

\section{PALAVRAS-CHAVE / KEYWORDS}

Desporto adaptado, Jogos Paralímpicos de Inverno, esqui adaptado, esqui alpino, esqui nórdico, para-hóquei no gelo

Adapted sport, Paralympic Winter Games, adapted skiing, alpine skiing, Nordic skiing, adapted-ice hockey

\section{Introdução}

Os desportos de Inverno são modalidades com um número crescente de praticantes em Portugal. É cada vez mais habitual na prática clínica encontrar doentes com lesões traumáticas adquiridas na prática desportiva durante os períodos de férias em países com neve. No esqui, as lesões mais frequentes são a rotura do ligamento cruzado anterior, outras entorses do joelho, fratura do rádio distal e concussão ou traumatismo craniencefálico. Por outro lado, no snowboard há maior prevalência de fraturas do rádio distal, fratura da clavícula, concussão cerebral e lesões do ligamento colateral medial do joelho. ${ }^{1} \mathrm{~A}$ prevenção de lesões com prescrição de programas de exercício dirigido e fortalecimento muscular adequado são altamente recomendados. ${ }^{2} \mathrm{~A}$ utilização de capacete é também considerada uma medida eficaz na diminuição da morbilidade. ${ }^{3 \cdot}$ A utilização de capacete demonstrou redução do risco de traumatismo craniencefálico e diminuição da gravidade dos mesmos, sem aumentar o risco de lesão medular cervical. ${ }^{4}$

Associando os desportos de Inverno às necessidades das pessoas com alteração da funcionalidade, independência e participação, sugiram os desportos de Inverno adaptados. À semelhança das restantes modalidades, também os desportos de Inverno são praticados por atletas paralímpicos e existem variadas opções de desportos de neve adaptados.

Os primeiros Jogos Paralímpicos de Inverno decorreram em 1976, em Ornskoldsvi, na Suécia. Os Jogos mais recentes foram realizados em 2018, em Pyeongchang na Coreia do Sul. Participaram mais de 500 atletas em seis modalidades: esqui alpino, esqui nórdico, curling, para-hóquei no gelo, snowboard e biatlo. das várias infraestruturas dos Jogos Olímpicos de 2008 que decorreram na mesma cidade.

Desde meados do século XX, no pós-Segunda Guerra Mundial, que o esqui é praticado como atividade recreativa por atletas portadores de deficiência, mais habitualmente, amputados. Os gestos técnicos e o equipamento utilizado foram influenciados por Paul Leimkuehler, um técnico de ortoprotesia que foi submetido a amputação de um membro inferior durante a Segunda Guerra Mundial. A participação no desporto adaptado mostrou melhorar a capacidade cardiovascular, contribuir positivamente para a saúde mental, integração na comunidade, diminuição da dor e melhores resultados em escalas de qualidade de vida. Mais especificamente, Wetterhahn et al. aplicaram as escalas Multidimensional Body-Self Relations Questionnaire (MBSRQ) e Amputee Body-Image Scale (ABIS) a dois grupos de doentes com amputação do membro inferior, sedentários e com atividade física regular, concluindo que os indivíduos que praticavam desporto apresentavam classificações significativamente mais altas. ${ }^{5}$ A minimização das alterações de perceção da autoimagem corporal relacionada à deficiência, permite melhor adesão a programas de exercício físico e de reabilitação. ${ }^{5}$

Quanto aos benefícios cardiovasculares, Campos et al. compararam a performance de atletas portadores de deficiência com atletas profissionais não portadores de deficiência. A modalidade estudada foi o futebol de salão. Este trabalho concluiu que a performance cardiorrespiratória e motora em atletas paralímpicos é inferior à de jogadores profissionais, mas superior à de jogadores semi-profissionais. ${ }^{6}$ Noutro estudo, verificou-se que o $\mathrm{VO}_{2}$ max de atletas paralímpicos é inferior ao de atletas profissionais não portadores de deficiência, mas semelhante ao de atletas semi-profissionais. ${ }^{7}$ Considerando que o consumo máximo de oxigénio é um indicador do limite máximo de tolerância ao exercício aeróbio, estes resultados sugerem que atletas com deficiência são menos tolerantes a 
esta modalidade de treino do que atletas profissionais sem deficiência, mas têm uma tolerância semelhante à de atletas semiprofissionais. ${ }^{7}$

Sterba et al. publicaram um estudo sobre a inclusão de jovens com paralisia cerebral em programas de prática de esqui. A paralisia cerebral inclui um espectro vasto de défices motores e posturais, causando limitação da atividade, que são atribuídos a distúrbios não progressivos ocorridos no desenvolvimento do cérebro fetal ou infantil. Neste estudo foram incluídos doentes com formas menos graves de paralisia cerebral espástica, que apresentavam capacidade para a marcha, com ou sem produtos de apoio. Os participantes realizaram sessões semanais de esqui, cada uma de 90 minutos, durante 10 semanas. As aulas incluíam vários instrutores e auxiliares que asseguravam a segurança dos participantes. Não se registaram lesões desportivas neste estudo. Verificou-se melhoria do equilíbrio, força muscular, independência na marcha e no subir/descer escadas. Verificou-se uma evolução clínica favorável em todos os participantes, com maior independência quanto à marcha, subir/descer escadas, transferências e alternância de decúbitos, tendo sido aplicado a todos o Gross Motor Function Classification System. ${ }^{8}$ Os autores destacam ainda o impacto positivo na qualidade de vida pela sensação de inclusão nas atividades desportivas. A melhoria na independência manteve-se quando os participantes foram reavaliados, 10 semanas após terminarem a intervenção.

Apesar da prática desportiva estar aconselhada para a população em geral e para pessoas portadoras de deficiência, esta não é isenta de riscos e associa-se a lesões. Quando se comparam os Jogos Paralímpicos

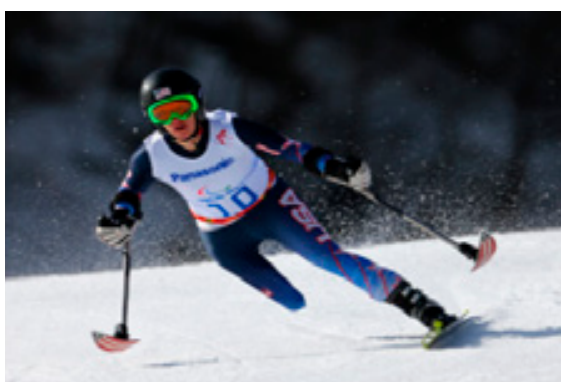

Figura 1 - Esqui alpino

Fonte: http://iranthisway.com/tag/dizin/ de inverno com os Jogos Paralímpicos, verifica-se maior incidência de contusões, fraturas e concussões, provavelmente devido à alta energia cinética da velocidade e aos impactos inerentes às modalidades. As úlceras de pressão são uma morbilidade frequente nos desportos de inverno adaptados devido à necessidade de utilização de dispositivos de equipamento adaptado. ${ }^{2,9}$

Segue-se uma breve descrição das adaptações necessárias e lesões típicas das três modalidades com mais participantes: esqui alpino, esqui nórdico e para-hóquei no gelo.

\section{Esqui alpino}

O esqui alpino adaptado envolve a utilização de esquis com suportes laterais, esquis com cadeira e monoesquis. Os atletas competem pelo melhor tempo de prova em percursos com variados obstáculos. Surgiu durante o século XX após o súbito aumento de atletas amputados em ferimentos de guerra que procuraram manter-se ativos na modalidade. Em 1967, foi criada a NASA (National Amputees Skiers Association), a qual foi a primeira organização oficial de desporto adaptado nos EUA. Algumas particularidades do esqui alpino adaptado são, por exemplo, o maior número de treinos no percurso antes da prova, pistas mais largas e a ausência de obstáculos que necessitem de saltos para serem ultrapassados. Os obstáculos têm declives menores do que no esqui alpino convencional.

\section{Esqui nórdico}

O esqui nórdico, ou de corta-mato, surgiu pela primeira vez nos Jogos

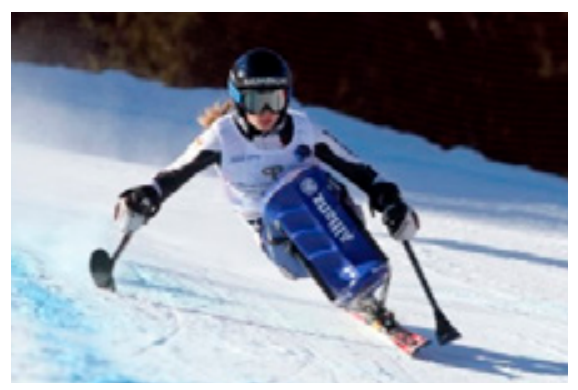

Figura 2 - Esqui nórdico

Fonte: https://www.youtube.com/ watch?v=Q6VME1FRy20
Paralímpicos de Inverno em 1976. O biatlo (esqui corta-mato e tiro ao alvo) foi incluído como desporto paralímpico em 1988. Atualmente participam nesta modalidade atletas com variados graus de incapacidade motora, mas também com alterações graves da acuidade visual. Para estes atletas existem sinais sonoros para garantir que se mantêm no percurso da prova. Quando comparado com o esqui alpino, o esqui nórdico tem menor incidência de lesões desportivas. ${ }^{10}$ Verificou-se que os atletas sitskier, que competem sentados em cadeira adaptada com lâmina de esqui, têm menor incidência de quedas e lesões quando comparados com os que competem com outros dispositivos de adaptação.

\section{Para-hóquei no gelo}

Trata-se de uma modalidade em crescimento, especialmente nos EUA, Canadá e Suécia. É praticado habitualmente por atletas com lesão vertebromedular ou lesões traumáticas e neurológicas crónicas que comprometam a função dos membros inferiores. Os atletas jogam sentados, num equipamento equiparável a um trenó. Uma das principais adaptações é que jogador utiliza dois sticks que servem simultaneamente para impulsionar a locomoção e para disputar o disco que permite a marcação de pontos. As regras da International Ice Hockey Federation aplicam-se ao para-hóquei no gelo. As lesões habituais nesta modalidade advêm habitualmente de momentos de colisão entre atletas durante a disputa do disco. Num estudo realizado nos Jogos Paralímpicos de Inverno de 2010, 47,5\% das lesões foram dos membros superiores, 35\% foram traumatismos da coluna

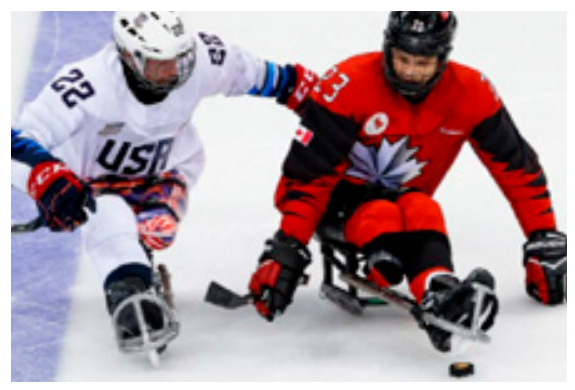

Figura 3 - Para-hóquei no gelo Fonte: https://www.cbc.ca/sports/paralympics/ice-hockey/united-states-canada-para-hockey-worlds-gold-recap-1.5123363 
vertebral e 10\% foram lesões dos membros inferiores. ${ }^{11} \mathrm{O}$ ombro, punho e mão foram as regiões mais frequentemente lesionadas.

\section{O equipamento}

O equipamento usado por atletas nos desportos paralímpicos de inverno varia, dependendo das incapacidades individuais. A segurança da prática destes desportos e a performance dos atletas tem vindo a melhorar muito com a utilização de novos materiais e evolução da tecnologia usada nas próteses, ortóteses, trenós e esquis. Apesar da variabilidade, foi estabelecido um regulamento para promover o fair- play e a equidade de oportunidades entre os participantes. São exemplos de adaptações regulamentadas: o comprimento, a largura e a espessura dos esquis e a altura das botas. As próteses utilizadas na prática do esqui diferem consoante a modalidade da prova. Por exemplo, uma vez que o esqui nórdico é uma prova de corta-mato, de percurso longo e exigente quanto à endurance do atleta, as próteses e os esquis são mais leves do que no esqui alpino. Nas provas de corta-mato os dispositivos utilizados são tendencialmente mais baixos e com um esqui mais curto para maior estabilidade. Uma vez que o esqui alpino é praticado em percursos curtos e muito mais acidentados, os esquis são mais longos, menos espessos e mais ágeis. ${ }^{12}$ Têm maior capacidade de amortecer o impacto dos obstáculos e declives.

\section{Conclusão}

As equipas médicas que trabalham com atletas paralímpicos de Jogos de Inverno têm de estar altamente preparadas, tanto para lesões agudas, como para as intercorrências e agudizações relacionadas com a patologia crónica de base, que é muito variada, sendo as mais comuns as lesões vertebromedulares, amputações e paralisia cerebral. Apesar da incidência de lesões associadas à prática desportiva em desportos adaptados, considera-se que os benefícios superam os riscos se houver uma equipa de apoio preparada, com programas de prevenção, recursos humanos (equipa multidisciplinar), técnicos e materiais.

As autoras declaram ausência de conflitos, assim como a originalidade do manuscrito e a sua não publicação prévia.

Correspondência

Margarida Freitas

Hospital Garcia de Orta - Av. Torrado da

Silva | 2805-267 Almada

margaridafmfreitas@gmail.com

\section{Bibliografia}

1. Weinstein S, Khodaee M, VanBaak K. Common Skiing and Snowboarding Injuries. Curr Sports Med Rep. 2019; 18(11):394-400.

2. Oh H, Johnson W, Syrop IP. Winter Adaptive Sports Participation, Injuries, and Equipment. Sports Med Arthrosc Rev. 2019; 27(2):56-59.

3. Steenstrup SE, Bakken A, Bere T, et al. Head injury mechanisms in FIS World Cup alpine and freestyle skiers and snowboarders. Br. J. Sports Med. 2018; 52:61-9.

4. Owens BD, Nacca C, Harris AP, Feller RJ. Comprehensive review of skiing and snowboarding injuries. J. Am. Acad. Orthop Surg. 2018; 26:e1-10.

5. Wetterhahn KA, Hanson C, Levy CE. Effect of participation in physical activity on body image of amputees. Am J Phys Med Rehabil. 2002; 81:194-201.

6. Luis F. C. C. Campos, João P. Borin, Tom Nightingale, Anselmo A. Costa E. Silva, Paulo F. Araújo, José I. Gorla. Alterations of Cardiorespiratory and Motor Profile of Paralympic 5-a-side Football Athletes during 14-Week In-Season Training. International Journal of Sports Science. 2014; 4(6A):85-90.

7. Álvarez, J. C. B., D’ottavio, S., Vera, J. G., \& Castagna, C. Aerobic fitness in futsal players of different competitive level. Journal of Strength and Conditioning Research. 2009; 23(7):2163-2166

8. Sterba JA. Adaptive Downhill skiing in children with cerebral palsy: effect on gross motor function. Pediatr Phys Ther. 2006; 18:289-296.

9. Ferrara MS, Buckley WE, Messner DG, et al. The injury experience and training history of the competitive skier with a disability. Am J Sports Med. 1992; 20:55-60.

10. Webborn N, Willick S, Reeser JC. Injuries among disabled athletes during the 2002 Winter Paralympic Games. Med Sci Sports Exerc. 2006; 38:811-815.

11. Webborn N, Willick S, Emery CA. The injury experience at the 2010 Winter Paralympic Games. Clin J Sport Med. 2012; 22:3-9.

12. International Paralympic Committee. IPC historical results archive. 2018. Disponível em: www.paralympic.org/sdms/hira/web/ competition/pyeongchang-2018. 